ARTICLE

\title{
Realizing high-power and high-capacity zinc/ sodium metal anodes through interfacial chemistry regulation
}

\author{
Zhen Hou (1) Yao Gao ${ }^{1}$, Hong $\operatorname{Tan}^{1}$ \& Biao Zhang (10 1,2,3凶
}

Stable plating/stripping of metal electrodes under high power and high capacity remains a great challenge. Tailoring the deposition behavior on the substrate could partly resolve dendrites' formation, but it usually works only under low current densities and limited capacities. Here we turn to regulate the separator's interfacial chemistry through tin coating with decent conductivity and excellent zincophilicity. The former homogenizes the electric field distribution for smooth zinc metal on the substrate, while the latter enables the concurrent zinc deposition on the separator with a face-to-face growth. Consequently, dendrite-free zinc morphologies and superior cycling stability are achieved at simultaneous high current densities and large cycling capacities $\left(1000 \mathrm{~h}\right.$ at $5 \mathrm{~mA} / \mathrm{cm}^{2}$ for $5 \mathrm{mAh} / \mathrm{cm}^{2}$ and $500 \mathrm{~h}$ at $10 \mathrm{~mA} / \mathrm{cm}^{2}$ for $10 \mathrm{mAh} / \mathrm{cm}^{2}$ ). Furthermore, the concept could be readily extended to sodium metal anodes, demonstrating the interfacial chemistry regulation of separator is a promising route to circumvent the metal anode challenges.

\footnotetext{
${ }^{1}$ Department of Applied Physics, The Hong Kong Polytechnic University, Hong Kong, China. ${ }^{2}$ The Hong Kong Polytechnic University Shenzhen Research Institute, Shenzhen, China. ${ }^{3}$ Guangdong-Hong Kong-Macao Joint Laboratory for Photonic-Thermal-Electrical Energy Materials and Devices, Research Institute for Smart Energy, The Hong Kong Polytechnic University, Hong Kong, China. ${ }^{凶}$ email: biao.ap.zhang@polyu.edu.hk
} 
A queous rechargeable batteries are promising alternatives to conventional Li-ion batteries for large-scale energy storage systems $^{1,2}$. The utilization of water solvent offers the advantages of low cost, high safety, and environmental benignity ${ }^{3,4}$. Besides, high ionic conductivities of aqueous media result in superior power densities ${ }^{5}$. Among various aqueous batteries, zinc metal batteries have attracted extensive attention, because $\mathrm{Zn}$ anodes are prized for high volumetric capacity $\left(5851 \mathrm{mAh} / \mathrm{cm}^{3}\right)$, abundant resources, and environmental friendliness ${ }^{6-8}$. Although primary $\mathrm{Zn}$ metal batteries (e.g., $\mathrm{Zn}-\mathrm{MnO}_{2}$ cells) have been commercialized and used, the practical application in rechargeable batteries is hindered by the formation of $\mathrm{Zn}$ dendrites ${ }^{9,10}$. It is well known that during $\mathrm{Zn}$ deposition, an uneven electric field distribution inevitably forms at the pores of the separator (Fig. 1a, c $)^{11,12}$. In addition, both $\mathrm{Zn}^{2+}$ and the electric field tend to concentrate at the protuberances with high surface energy ${ }^{13}$. Therefore, zinc nucleation and growth prefer to occur at such tips (i.e., "tip effect") ${ }^{13}$, resulting in inhomogeneous $\mathrm{Zn}$ deposition. The formed $\mathrm{Zn}$ protrusions further increase the local electric field intensity around them, leading to the evolution of $\mathrm{Zn}$ protuberances into $\mathrm{Zn}$ dendrites upon cycling. In particular, high current density and large cycling capacity significantly exacerbate the formation of $\mathrm{Zn}$ dendrites, thus dramatically restricting the power and energy density of $\mathrm{Zn}$ metal batteries ${ }^{14}$. Specifically, at higher current densities, the $\mathrm{Zn}^{2+}$ around the electrode/electrolyte interface are rapidly depleted ${ }^{15-17}$. Subsequently, the dendrites are formed and quickly render a short circuit of cells. Higher cycling capacity would bring about greater volume change, which leads to the pulverization of $\mathrm{Zn}$ foil and may make $\mathrm{Zn}$ dendrites lose contact with the electrodes, becoming "dead $\mathrm{Zn}$ "13,18. This would finally give rise to a low reversibility for the $\mathrm{Zn}$ deposition/stripping process.

Various strategies have been developed to tackle the above issues, including designing hierarchical electrode structures ${ }^{19-25}$, modifying electrolyte formulations ${ }^{26-30}$, and optimizing charge/ discharge protocols $\mathrm{s}^{31,32}$. Constructing advanced electrode/electrolyte and separator/electrolyte interfaces are also regarded as an effective approach to stabilize $\mathrm{Zn}$ metal anodes through controlling the $\mathrm{Zn}$ deposition behavior ${ }^{33-43}$. For example, Kang and colleagues $^{33}$ reports that an indium layer coated $\mathrm{Zn}$ metal anode could bring about the uniform $\mathrm{Zn}^{2+}$ flux and anti-corrosion capability, thus enabling a running lifetime of $\sim 500 \mathrm{~h}$ at $1 \mathrm{~mA} / \mathrm{cm}^{2}$ and $1 \mathrm{mAh} / \mathrm{cm}^{2}$. Recently, vertical graphene is introduced into the separator to effectively homogenize electric field distribution and $\mathrm{Zn}^{2+}$ flux ${ }^{41}$, which suppresses the $\mathrm{Zn}$ dendrites growth and realizes improved cycle life of $\sim 80 \mathrm{~h}\left(5 \mathrm{~mA} / \mathrm{cm}^{2}, 5 \mathrm{mAh} / \mathrm{cm}^{2}\right)$ and $\sim 600 \mathrm{~h}\left(10 \mathrm{~mA} / \mathrm{cm}^{2}, 1 \mathrm{mAh} / \mathrm{cm}^{2}\right)$.

Despite these exciting progress, achieving long-term cyclic stability for $\mathrm{Zn}$ plating/stripping remains a great challenge, especially at simultaneous high current density $\left(>5 \mathrm{~mA} / \mathrm{cm}^{2}\right)$ and large cycling capacity $\left(>5 \mathrm{mAh} / \mathrm{cm}^{2}\right)^{14}$. At present, most of the reported works stabilize $\mathrm{Zn}$ metal anodes through suppressing the $\mathrm{Zn}$ dendrite growth. However, the formation of $\mathrm{Zn}$ dendrites is inherently unavoidable, notably at rigorous testing conditions, as such a process is thermodynamically and kinetically favorable ${ }^{15,44}$. Therefore, it is highly desirable to develop a unique strategy that could not only restrain the $\mathrm{Zn}$ dendrites initiation but also eliminate inevitably formed $\mathrm{Zn}$ dendrites.

In this work, we construct metallic Sn-coated separator via magnetron sputtering to stabilize $\mathrm{Zn}$ metal anodes. The highly conductive Sn coating with excellent zincophilicity could help to homogenize $\mathrm{Zn}^{2+}$ flux (as simulated by the finite element method) and meanwhile manipulate the growth direction of $\mathrm{Zn}$ metal. Thanks to these synergetic effects, dramatically improved cycle life of $1000 \mathrm{~h}\left(5 \mathrm{~mA} / \mathrm{cm}^{2}, 5 \mathrm{mAh} / \mathrm{cm}^{2}\right)$ and $500 \mathrm{~h}(10 \mathrm{~mA} /$ $\mathrm{cm}^{2}, 10 \mathrm{mAh} / \mathrm{cm}^{2}$ ) are realized on $\mathrm{Zn} / \mathrm{Zn}$ symmetric cells. Furthermore, we demonstrate that the approach could be readily extended to $\mathrm{Na} / \mathrm{K}$ metal anodes for enabling safe and highperformance $\mathrm{Na} / \mathrm{K}$ metal batteries.

\section{Results}

Mechanism of controllable dendrites growth. We propose the use of separators modified with conductive and zincophilic coatings to build smooth $\mathrm{Zn}$ deposition on both the anode and separator, which helps to stabilize Zn metal anodes at high current densities and large cycling capacities. A nonuniform electric field distribution commonly exists due to the concentrated electric field on the pores of pristine separator ${ }^{11}$. The introduction of conductive layer on the separator is expected to homogenize the electric field between the separator and the anode due to the equipotential surface of the conductor ${ }^{45,46}$. The excellent zinc affinity of the coating would be beneficial to facilitating the uniform transport of $\mathrm{Zn}^{2+}$ towards the anode under the homogeneous electric field ${ }^{47,48}$. Effect of the conductive coating on
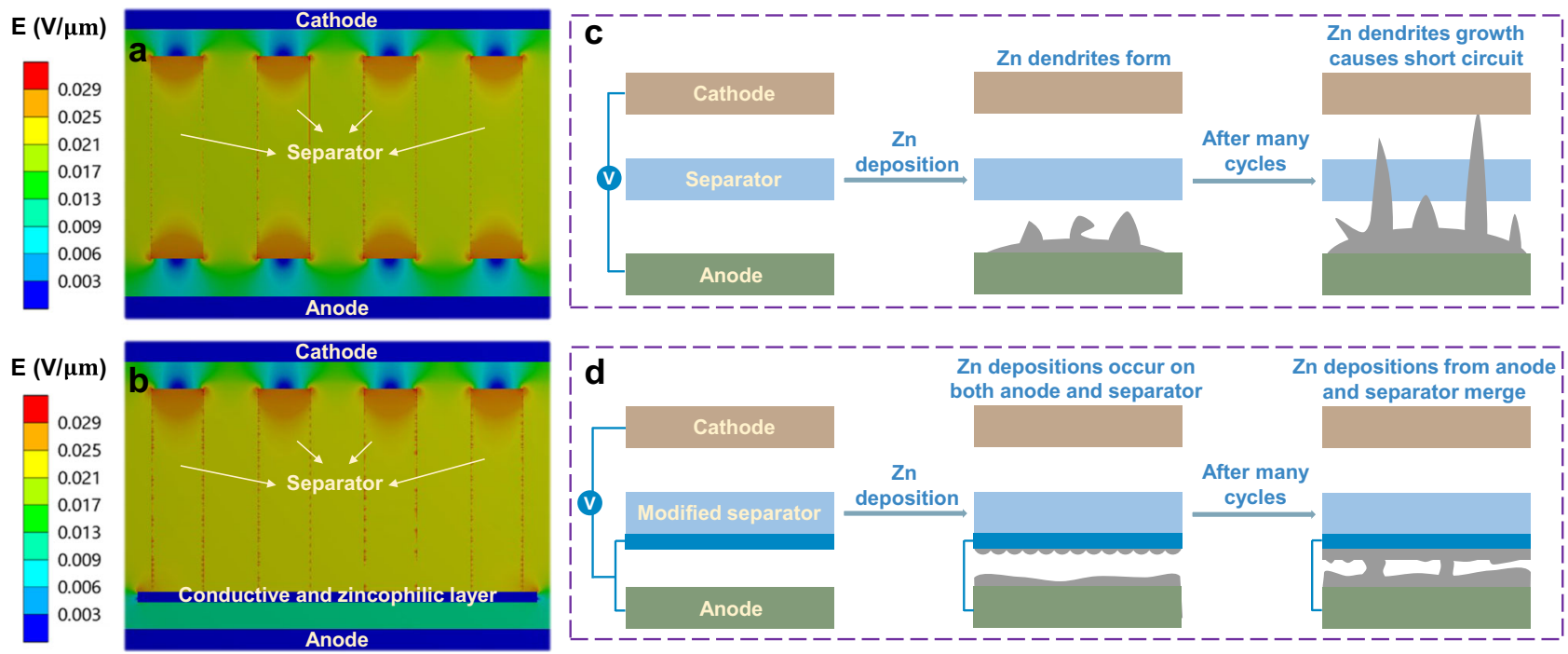

Fig. 1 Theoretical calculation and protection mechanism of modified separator. a Electric field distribution with the pristine separator. $\mathbf{b}$ Electric field distribution in the non-contact region of the modified separator and the anode. c Schematic illustration of $Z n$ deposition with the pristine separator. d Schematic illustration of $\mathrm{Zn}$ deposition in the contact region of the modified separator and the anode (see Supplementary Note 1 for details). 
electric field distribution is simulated by the finite element method (Supplementary Figs. 1-3 and Supplementary Note 1). As shown in Fig. 1a and Supplementary Movie 1, the electric field intensity on the pores of pristine separator is obviously higher than that of the adjacent cellulose skeletons, which would give rise to severely nonuniform $\mathrm{Zn}$ deposition on the anode. Such preferential $\mathrm{Zn}$ deposition further evolves into $\mathrm{Zn}$ dendrites through self-amplification mechanism, eventually causing the internal short circuit of cells (Fig. 1c). On the contrary, a uniform electric field is observed after introducing the conductive layer on separator due to its equipotential surface (Fig. $1 \mathrm{~b}$ and Supplementary Movie 2). Notably, such enhancement is applied for the region where the Sn coating is not in contact with the anode. The zincophilic nature of the coating would help to generate the homogenous $\mathrm{Zn}^{2+}$ flux under this uniform electric field, in turn enabling a smooth $\mathrm{Zn}$ deposition on the anode. Meanwhile, within the region where Sn coating is in contact with the anode, a highly zincophilic coating layer will trigger the concurrent $\mathrm{Zn}$ deposition on the separator (Fig. 1d) ${ }^{49,50}$. Upon cycling, the $\mathrm{Zn}$ depositions from the anode and the separator will meet and merge, enabling a compact morphology. Furthermore, the direction of $\mathrm{Zn}$ growth changes from perpendicular to parallel, to the separator, which prevents it from piercing through the separator.

Screening and fabrication of appropriate coatings on separator. Based on the above-proposed mechanism, a superior coating on separator should meet the following requirements: (1) be water insoluble and have a higher redox potential than $\mathrm{Zn}$ metal to avoid electrochemical oxidation; (2) possess zincophilic nature for attracting $\mathrm{Zn}^{2+}$ to coating/electrolyte interface; and (3) have a decent electric conductivity to yield an equipotential surface and provide electrons for reducing $\mathrm{Zn}^{2+}$ into $\mathrm{Zn}$. Thus, inherently conductive metals with an applicable redox potential and favorable zincophilicity would be promising coating candidates. To screen the ideal metal elements, we compare the zincophilicity of various metals with eligible redox potentials, including $\mathrm{Sn}, \mathrm{Ag}, \mathrm{Bi}$, and $\mathrm{Sb}$. Metal slurries are cast on $\mathrm{Ti}$ foils to fabricate corresponding metal-modified $\mathrm{Ti}$ foils (denoted as metal-Ti), to investigate their zincophilicity. The value of nucleation overpotential $(\eta)$ is used to evaluate the zincophilicity of these species. Here, $\eta$ is calculated according to the potential difference between the voltage tip and subsequent stable voltage ${ }^{51}$. As shown in Fig. 2a, Supplementary Fig. 4, and Supplementary Note 2, $\eta$ of the bare Ti current collector is $44 \mathrm{mV}$. The Sn-Ti current collector presents the lowest $\eta$ of $8 \mathrm{mV}$ among these metals, followed by Ag-Ti $(16 \mathrm{mV}), \mathrm{Bi}-\mathrm{Ti}(19 \mathrm{mV})$, and Sb-Ti $(49 \mathrm{mV})$. Therefore, the Sn element will be an optimal candidate to prepare the highquality coating on the separator. To figure out the reason of the excellent affinity between $\mathrm{Sn}$ and $\mathrm{Zn}$, the electrochemical behavior of $\mathrm{Sn}-\mathrm{Ti} / \mathrm{Zn}$ cell is investigated. First, the cyclic voltammetry (CV) curve of $\mathrm{Sn}-\mathrm{Ti} / \mathrm{Zn}$ cell between 0.01 and $0.6 \mathrm{~V}$ is collected to show whether there are any alloy reactions between them. A cathodic peak at $\sim 0.28 \mathrm{~V}$ and two anodic peaks at 0.38 and $0.47 \mathrm{~V}$ are observed (Fig. 2b and Supplementary Fig. 5), which should be assigned to the alloying and dealloying between $\mathrm{Sn}$ and $\mathrm{Zn}$. The discharge curve of the Sn-Ti/Zn cell is collected at $0.08 \mathrm{~mA} / \mathrm{cm}^{2}$ (the cut-off voltage is $0.01 \mathrm{~V}$ ) and it could deliver a discharge capacity of $21 \mathrm{mAh} / \mathrm{g}$ (based on the mass of Sn) (Fig. 2c), which further confirms the alloy reaction and explains the superb affinity between $\mathrm{Zn}$ and $\mathrm{Sn}^{52}$. The alloy reaction results in the $\mathrm{X}$-ray diffraction (XRD) peak shift of pristine $S n$ to lower angle after discharge (Supplementary Fig. 6). Furthermore, the X-ray photoelectron spectroscopy (XPS) spectra of pristine and discharged $\mathrm{Sn}$ also reveal alloy reaction (Fig. 2d). The formation of $\mathrm{Zn}-\mathrm{Sn}$
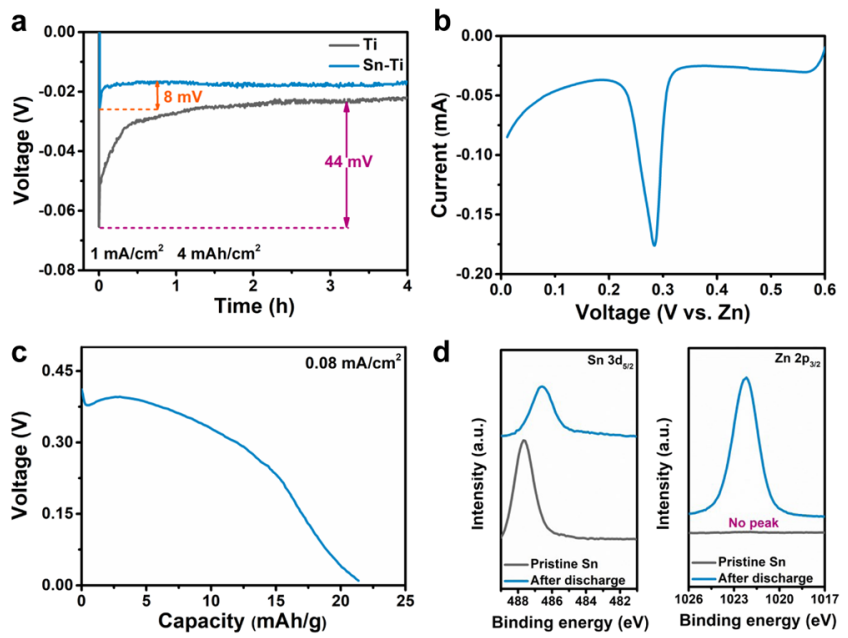

Fig. 2 The alloy reaction between $\mathrm{Sn}$ and $\mathrm{Zn}$. a The nucleation overpotential of $\mathrm{Zn}$ on Ti and Sn-Ti current collectors; $\mathbf{b} \mathrm{CV}$ of $\mathrm{Sn}$-Ti/Zn cell at a scan rate of $0.2 \mathrm{mV} / \mathrm{s}$; $\mathbf{c}$ the galvanostatic discharge curve of $\mathrm{Sn}-\mathrm{Ti} / \mathrm{Zn}$ cell at $0.08 \mathrm{~mA} / \mathrm{cm}^{2}$; and $\mathbf{d}$ XPS spectra of $\mathrm{Sn} 3 d$ and $\mathrm{Zn} 2 p$ for pristine and discharged Sn.

alloy alters the electronic states of Sn, bringing about a downshift of the $\mathrm{Sn} 3 d_{5 / 2}$ peak from $487.6 \mathrm{eV}$ for the pristine one to $486.6 \mathrm{eV}$ after discharge ${ }^{53,54}$. Meanwhile, a new $\mathrm{Zn} 2 p_{5 / 2}$ peak at $1022.2 \mathrm{eV}$ is detected in the discharged sample, confirming the formation of $\mathrm{Zn}$-Sn alloy.

Magnetron sputtering is easy to handle and is reproducible, allowing a precise thickness control (Supplementary Fig. 7 and Supplementary Note 3 ) of the film at the nanoscale level ${ }^{55}$. These characteristics give it unparalleled advantages to prepare Sncoated separator. We focus on the modified separator with a sputtering time of $1 \mathrm{~min}$, because it has the best performance in stabilizing $\mathrm{Zn}$ metal anodes. As seen from optical images (Fig. 3a, b), a gray Sn coating is constructed on the white pristine separator after sputtering. The average mass loading of Sn coating is only $\sim 0.06 \mathrm{mg} / \mathrm{cm}^{2}$, which is $<3 \%$ of the pristine separator $(\sim 2.14 \mathrm{mg} /$ $\mathrm{cm}^{2}$ ), having a negligible impact on the energy density of the battery. The scanning electron microscopy (SEM) images show that the separator is uniformly covered by Sn particles with an average diameter of $\sim 60 \mathrm{~nm}$. The corresponding energy dispersive spectroscopy mapping further proves the Sn elements are evenly distributed on the separator (Supplementary Fig. 8). The peaks of Sn-coated separator in XRD are assigned to tetragonal Sn (JCPDS\#65-2631) (Fig. 3c). The stability of such Sn layer in electrolyte is assessed through comparing the XPS and Raman spectra of pristine $\mathrm{Sn}$-coated separator with that after 20 cycles. It is observed that the $\mathrm{Sn}$ metal on the separator is highly resistant to oxidation in the aqueous electrolyte (see Supplementary Fig. 9 for details). The $\eta$ value of Ti/Zn cell with pristine and Sn-coated separator are compared, to demonstrate whether the $\mathrm{Zn}$ deposition could simultaneously take place on the modified separator. As shown in Fig. 3d, the Ti/Zn cell with Sn-coated separator has an $\eta$ of $28 \mathrm{mV}$, which is much lower than that using pristine one $(44 \mathrm{mV})$. Such a small $\eta$ reflects that the $\mathrm{Zn}$ deposition should be initiated on the zincophilic Sn-coated separator instead of the Ti current collector.

Morphologies of $\mathrm{Zn}$ deposition on the Sn-coated separator. Above results indicate that $\mathrm{Zn}$ would deposit on the Sn-coated separator. To confirm this conjecture, SEM images of Ti current collector and Sn-coated separator retrieved from cycled Ti/Zn cells are collected. Under a deposition capacity of $1 \mathrm{mAh} / \mathrm{cm}^{2}$, 

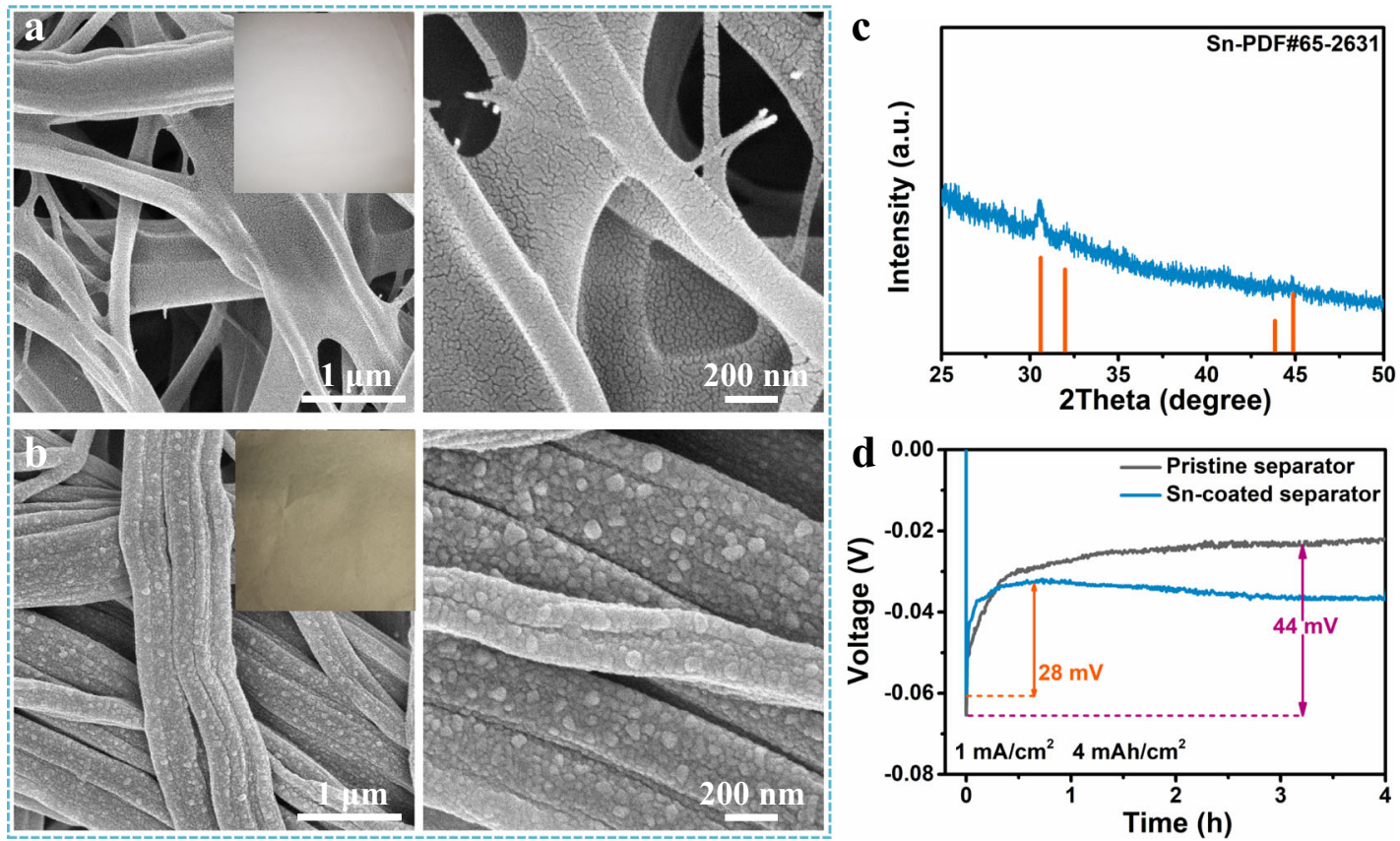

Fig. 3 Characterization of Sn-coated separator. The SEM images of a pristine separator and $\mathbf{b}$ Sn-coated separator with the corresponding optical photos in the insets. c The XRD spectrum of Sn-coated separator. $\mathbf{d}$ The nucleation overpotential of Ti/Zn cell with pristine separator and Sn-coated separator.

loose structures with uneven $\mathrm{Zn}$ chaotic clusters are observed on Ti current collector using the pristine separator (Fig. 4a). With an increasing deposition capacity of $4 \mathrm{mAh} / \mathrm{cm}^{2}, \mathrm{Zn}$ maintains similar dreadful morphology with sharp tips presented (Fig. 4b), which might pierce the separator upon cycling. Such notorious structures may result from the inhomogeneous nucleation and deposition of $\mathrm{Zn}$ due to the uneven electric field distribution, which inevitably forms at the pores of the separator (Fig. 1a, c). The uneven deposition of $\mathrm{Zn}$ further evolves into $\mathrm{Zn}$ dendrites through self-amplification mechanism. By contrast, the Ti current collector in the cell using Sn-coated separator present a much improved $\mathrm{Zn}$ deposition behavior. Specifically, dense and uniform $\mathrm{Zn}$ coatings are obtained under the capacity of both 1 and $4 \mathrm{mAh} /$ $\mathrm{cm}^{2}$ (Fig. 4c, d). The dendrite-free morphologies should be attributed to the homogenous electric field enabled by the Sn coating on the separator, which agrees well with the simulation results of finite element method (Fig. 1b). The corresponding SEM images of Sn-coated separator verify that the $\mathrm{Zn}$ deposition could be realized on the separator. A smooth layer of $\mathrm{Zn}$ is observed on the separator under a deposition capacity of $1 \mathrm{mAh} /$ $\mathrm{cm}^{2}$ (Fig. 4e and Supplementary Fig. 10). Moreover, the $\mathrm{Zn}$ deposition remains uniform at a higher deposition capacity (4 $\mathrm{mAh} / \mathrm{cm}^{2}$ ) (Fig. 4f). Therefore, the Sn coating enables the smooth $\mathrm{Zn}$ growth on both the separator and current collector, which will merge at later stages to suppress the dendrite growth.

Electrochemical performances of Sn-coated separator for $\mathrm{Zn}$ metal batteries. To elucidate the effect of Sn-coated separator, the coulombic efficiency (CE) of $\mathrm{Ti} / \mathrm{Zn}$ and cycling performances of $\mathrm{Zn} / \mathrm{Zn}$ symmetric cells using pristine and Sn-coated separators are evaluated. CE is a critical parameter to evaluate the reversibility of $\mathrm{Zn}$ deposition/stripping, which is calculated based on the capacity ratio of stripping to plating. The cells using Sn-coated separator show high and stable CE values compared with that using pristine separator (Supplementary Fig. 11 and Supplementary Note 4). Moreover, a rapid short circuit is observed on the cell using the pristine separator, indicating rampant $\mathrm{Zn}$ dendrite growth during the plating/stripping process. Therefore,
Sn-coated separator allows for better Zn reversibility and suppresses the growth of $\mathrm{Zn}$ dendrites. Turning to cycling stability, as shown in Supplementary Fig. 12 and Fig. 5a, Zn/Zn cell with pristine separator suffers from sudden voltage drop after $\sim 900 \mathrm{~h}$ $\left(1 \mathrm{~mA} / \mathrm{cm}^{2}\right.$ and $\left.1 \mathrm{mAh} / \mathrm{cm}^{2}\right)$ and $\sim 250 \mathrm{~h}\left(2 \mathrm{~mA} / \mathrm{cm}^{2}\right.$ and $2 \mathrm{mAh} /$ $\mathrm{cm}^{2}$ ), which is ascribed to a short circuit caused by the growth of $\mathrm{Zn}$ dendrites. The more rapid cell failure is observed at higher current densities and cycling capacities (Fig. 5b, c). Concretely, the cells experience short circuits at $\sim 170 \mathrm{~h}\left(5 \mathrm{~mA} / \mathrm{cm}^{2}\right.$ and $\left.5 \mathrm{mAh} / \mathrm{cm}^{2}\right)$ and $\sim 80 \mathrm{~h}\left(10 \mathrm{~mA} / \mathrm{cm}^{2}\right.$ and $\left.10 \mathrm{mAh} / \mathrm{cm}^{2}\right)$. This is due to the rampant dendrites growth induced by the local electric field intensity and depleted $\mathrm{Zn}^{2+}$ concentration at the electrode/ electrolyte interface. In contrast, stable cycle life up to $4500 \mathrm{~h}$ and $3800 \mathrm{~h}$ with a stable overpotential is respectively realized in the cell with Sn-coated separator at the condition of $1 \mathrm{~mA} / \mathrm{cm}^{2}$ for $1 \mathrm{mAh} / \mathrm{cm}^{2}$ and $2 \mathrm{~mA} / \mathrm{cm}^{2}$ for $2 \mathrm{mAh} / \mathrm{cm}^{2}$. Remarkably, Sncoated separator enables steady cycling for $1000 \mathrm{~h}$ at $5 \mathrm{~mA} / \mathrm{cm}^{2}$ for $5 \mathrm{mAh} / \mathrm{cm}^{2}$. An exceptional $\mathrm{Zn}$ plating/stripping life of $500 \mathrm{~h}$ could be achieved at a higher current density of $10 \mathrm{~mA} / \mathrm{cm}^{2}$ and cycling capacity of $10 \mathrm{mAh} / \mathrm{cm}^{2}$, indicating its excellent potential for practical use.

The cycle life of our work and previous reports is summarized in Supplementary Table 1. It is observed that symmetric batteries using Sn-coated separator have absolutely leading cycling stability at multiple current densities and cycling capacities. To better compare the cycling performance of symmetrical cells at different test conditions, the cumulative capacity ${ }^{56}$ (current density $\times$ cycle life) vs. the per-cycle areal capacity is plotted in Fig. $5 \mathrm{~d}$ (based on the data summarized in Supplementary Table 1). Figure $5 \mathrm{~d}$ contains the three key parameters of cycle life, current density, and cycling capacity (per-cycle areal capacity), which can provide a comprehensive picture of the electrochemical performance of symmetric batteries. This work delivers a high cumulative capacity of $7600 \mathrm{mAh} / \mathrm{cm}^{2}\left(2 \mathrm{~mA} / \mathrm{cm}^{2}\right)$ at a cycling capacity of $2 \mathrm{mAh} / \mathrm{cm}^{2}$, surpassing the value in most previous works. Moreover, cumulative capacity of more than $5000 \mathrm{mAh} / \mathrm{cm}^{2}$ at $5 \mathrm{~mA} / \mathrm{cm}^{2}$ and $10 \mathrm{~mA} / \mathrm{cm}^{2}$ is respectively realized at high cycling capacities of $5 \mathrm{mAh} / \mathrm{cm}^{2}$ and $10 \mathrm{mAh} / \mathrm{cm}^{2}$. Notably, such high cumulative capacities cannot be achieved at simultaneously high 

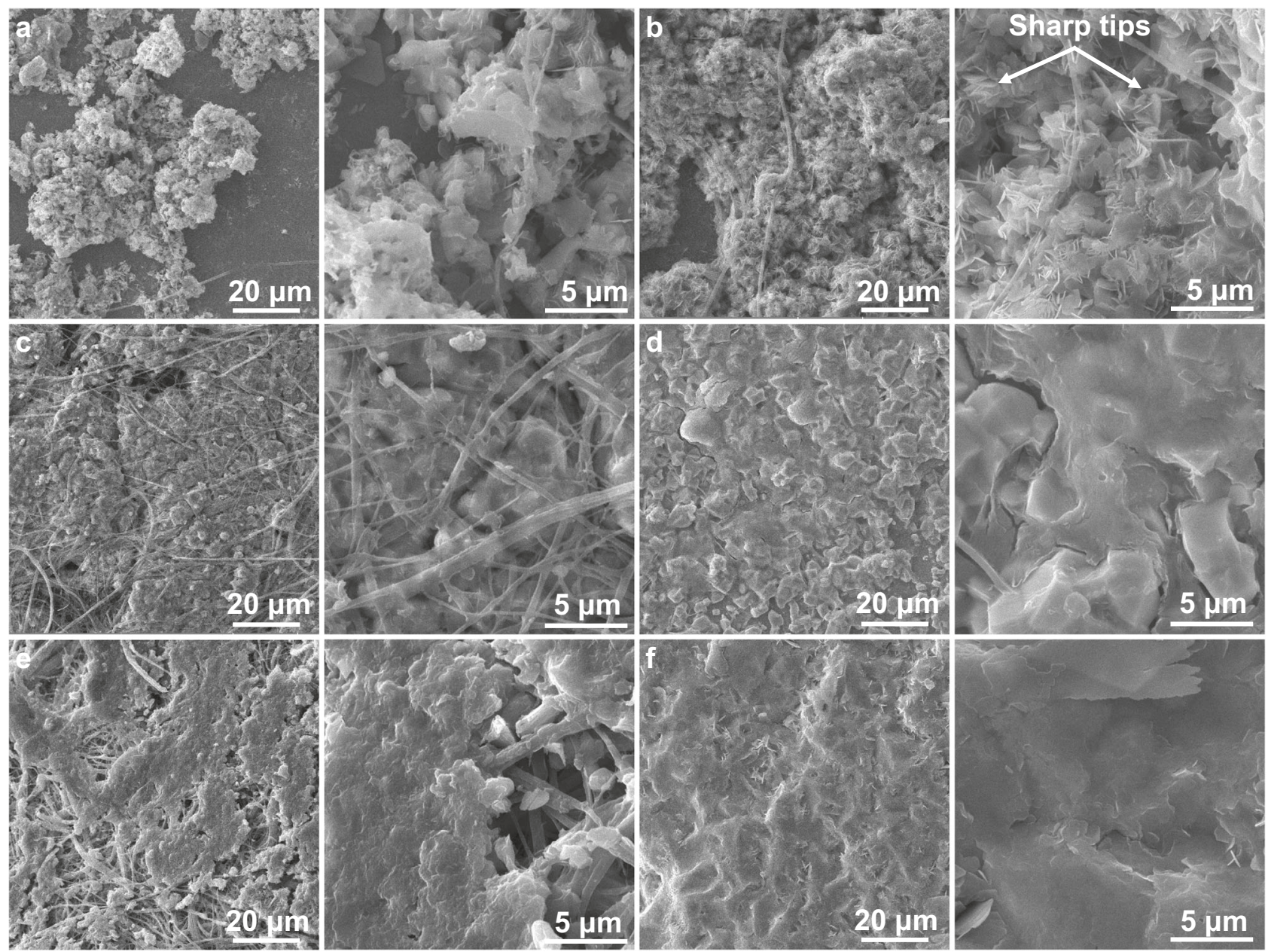

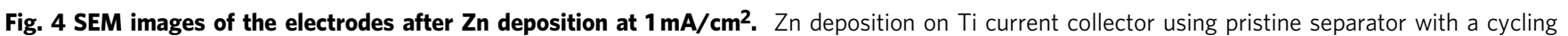

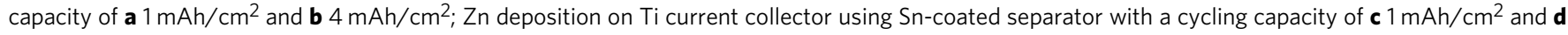
$4 \mathrm{mAh} / \mathrm{cm}^{2} ; \mathrm{Zn}$ deposition on Sn-coated separator with a cycling capacity of e $1 \mathrm{mAh} / \mathrm{cm}^{2}$ and $\mathbf{f} 4 \mathrm{mAh} / \mathrm{cm}^{2}$.

current density and large per-cycle areal capacity in previously reported approaches. These results clearly demonstrate the great superiority of our technique at a wide range of current densities and cycling capacities.

The mechanism behind improved cycling stability is further explored by the electrochemical impedance spectroscopy (EIS) and SEM images after cycles. The EIS data are simulated by equivalent circuits (Supplementary Fig. 14). An additional parallel resistor-capacitor circuit is incorporated for Sn-coated separator due to the presence of an extra depressed semicircle that is related to the $\mathrm{Sn}$ coating/electrolyte interface. The fitting resistance results are shown in Supplementary Table 2. The charge transfer resistance at the $\mathrm{Zn} /$ electrolyte interface $\left(R_{\mathrm{ct}}\right)$ of $\mathrm{Zn} / \mathrm{Zn}$ cells with pristine separator is $42.14 \Omega$ after 10 cycles and then increases to $73.69 \Omega$ after 20 cycles. In contrast, $\mathrm{Zn} / \mathrm{Zn}$ cells with $\mathrm{Sn}$-coated separator present stable and much lower resistances. The resistance at the $\mathrm{Sn}$ coating/electrolyte interface $\left(R_{\mathrm{sf}}\right)$ and $R_{\mathrm{ct}}$ only slightly rise from $5.81 \Omega$ and $2.26 \Omega$ in the 10 cycles to 6.61 $\Omega$ and $2.81 \Omega$ after the 20 cycles, respectively. The low and stable interfacial resistances indicate the enhanced deposition/stripping kinetics and interfacial stability. The SEM images after cycling provide further concrete evidence (Supplementary Fig. 15). An uneven surface with many protrusions is observed on $\mathrm{Zn}$ anode using pristine separator after one cycle due to inhomogeneous $\mathrm{Zn}$ deposition. Moreover, the cycled $\mathrm{Zn}$ evolves into a looser and rougher structure after 20 cycles. Benefiting from the uniform
$\mathrm{Zn}^{2+}$ flux by Sn coating, $\mathrm{Zn}$ anode presents a much smooth and uniform surface after 1 cycle and 20 cycles. Turn to the SEM images of cycled Sn-coated separator, it is partially covered by the flat $\mathrm{Zn}$ after one cycle. The dense $\mathrm{Zn}$ metal is observed on Sncoated separator after 20 cycles. The $\mathrm{Zn}$ depositions growing from anode and separator are supposed to meet and merge upon cycling, which gives rise to the compact $\mathrm{Zn}$ metal layer and changes the $\mathrm{Zn}$ growth direction. This is confirmed by dendritefree $\mathrm{Zn}$ morphologies on both $\mathrm{Zn}$ anode and $\mathrm{Sn}$-coated separator even after 200 cycles (Supplementary Fig. 16). These results indicate $\mathrm{Sn}$-coated separator could homogenize $\mathrm{Zn}^{2+}$ flux and merge $\mathrm{Zn}$ deposition from the substrate and separator, which leads to the dendrites-free morphologies and reinforced interfacial stability, realizing the safe operation of the cells even at rather rigorous testing conditions. It is noteworthy that the superior performance is realized with neither Sn-coated $\mathrm{Zn}$ foils nor other metal-coated separator (Supplementary Figs. 17-19 and Supplementary Note 5). It suggests a synergistic effect between the Sn-induced highly zincophilicity and the face-to-face growth in suppressing dendrite growth. Lastly, we explore the effect of Sn coating thickness for stabilizing $\mathrm{Zn}$ metal anode by varying the sputtering time (Supplementary Figs. 20-22). The results demonstrate that precise tuning of the Sn coating thickness at the nanoscale level, where magnetron sputtering shows great advantages over classic doctor-blade coating (Supplementary Figs. 23 and 24, and Supplementary Note 6), is essential to 

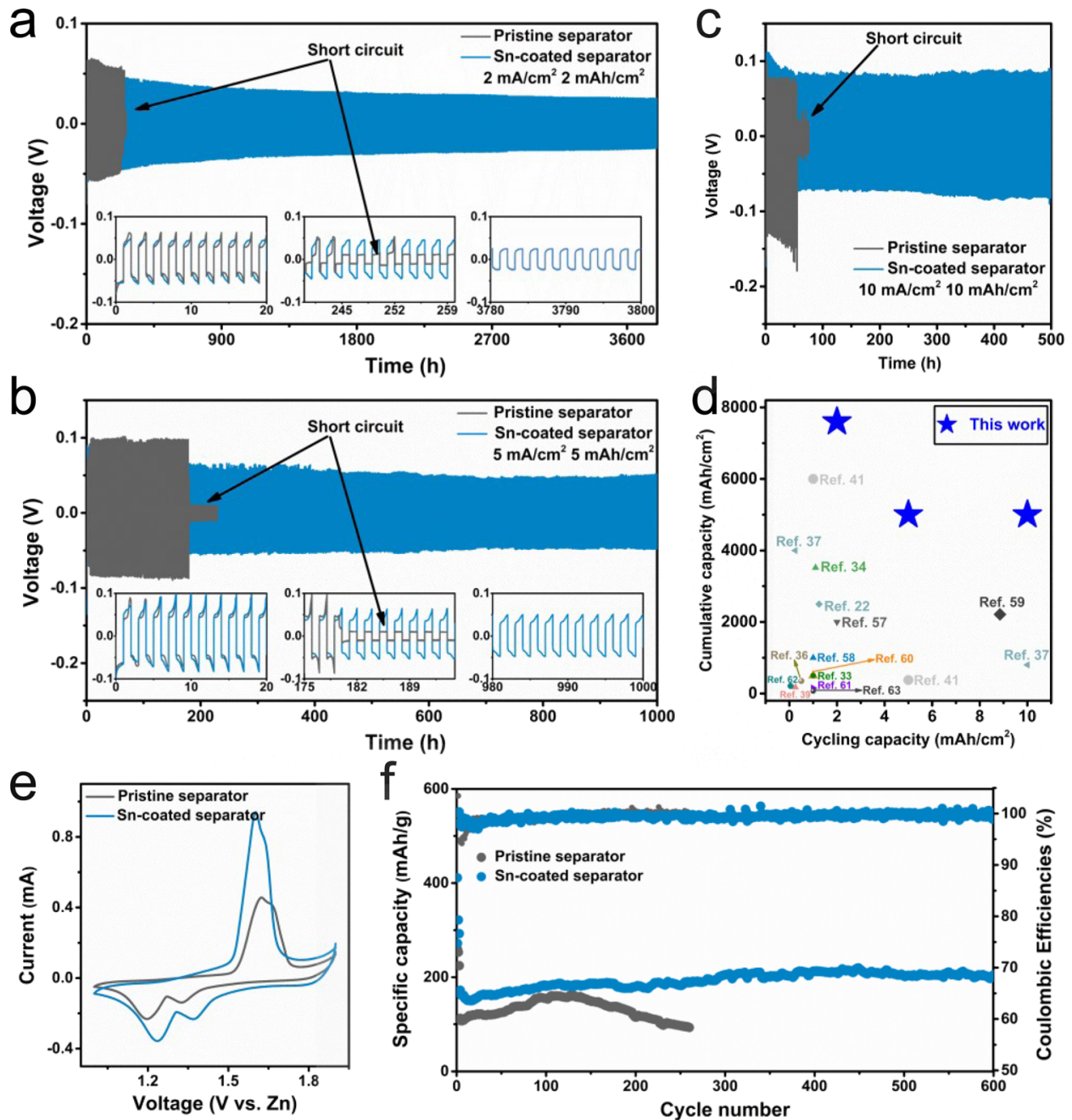

Fig. 5 The electrochemical performances of $\mathbf{Z n}$ metal batteries. The cycling performances of $\mathrm{Zn} / \mathrm{Zn}$ cells using pristine separator and Sn-coated separator tested at a $2 \mathrm{~mA} / \mathrm{cm}^{2}$ and $2 \mathrm{mAh} / \mathrm{cm}^{2}$, b $5 \mathrm{~mA} / \mathrm{cm}^{2}$ and $5 \mathrm{mAh} / \mathrm{cm}^{2}$, and $\mathbf{c} 10 \mathrm{~mA} / \mathrm{cm}^{2}$ and $10 \mathrm{mAh} / \mathrm{cm}^{2}$. d Comparison of cycling performance (cumulated capacity vs. cycling capacity) in this work and previously reported works (vertical graphene separator ${ }^{41}$; polyacrylonitrile separator ${ }^{39}$; reduced graphene oxide coated $\mathrm{Zn}^{65}$; carbon-coated $\mathrm{Zn}^{66} ; \mathrm{PVDF}^{\mathrm{TiO}} \mathrm{Ti}_{2}$ layer $67 ; \mathrm{ZnO}$ coating 22 ; polyamide coating 37 ; Kaolin layer ${ }^{34} ; \mathrm{Al}_{2} \mathrm{O}_{3} \mathrm{coating}^{68} ; \mathrm{TiO}_{2}$ coating ${ }^{69}$; indium layer ${ }^{33}$; MOF layer ${ }^{36} ; \mathrm{CaCO}_{3}$ coating ${ }^{70}$; and polyacrylamide separator ${ }^{71}$ ). The electrochemical performances of $\mathrm{Zn} \| \mathrm{MnO}_{2}$ batteries using pristine separator and Sn-coated separator: e CV at a scan rate of $0.1 \mathrm{mV} / \mathrm{s}$ (second cycle); $\mathbf{f}$ cycling performances at $0.3 \mathrm{~A} / \mathrm{g}$, with $\mathrm{Zn}$ foil as the anode.

achieving the superior performance, especially under stringent test conditions.

To assess the practical application of Sn-coated separator, the full cell paired with a $\mathrm{MnO}_{2}$ cathode (Supplementary Fig. 25) is assembled. The CV curves of full cells using pristine separator and Sn-coated separator are compared in Fig. 5e. They present the same Mn-ion redox peaks, which agrees well with the previous works ${ }^{57}$. The full cell with $\mathrm{Sn}$-coated separator shows lower oxidation potential, higher reduction potential, and peak current than that with pristine separator, suggesting improved reaction kinetics for Sn-coated separator ${ }^{34,58,59}$. Supportive evidence could be found at the rate performances of full cells (Supplementary Fig. 26). At a high current density of $0.75 \mathrm{~A} / \mathrm{g}$ (equivalent to 2C), a full cell with the Sn-coated separator can provide a discharge capacity equivalent to approximately $200 \%$ of that with the pristine separator $(107 \mathrm{mAh} / \mathrm{g}$ vs. $53 \mathrm{mAh} / \mathrm{g})$.

The long-term cycling stability of full cells using $\mathrm{Zn}$ foil as an anode is evaluated at $0.3 \mathrm{~A} / \mathrm{g}$. Benefitting from effective $\mathrm{Sn}$-coated separator, the full cell presents a stable cycle life with a discharge capacity of $\sim 200 \mathrm{mAh} / \mathrm{g}$ after 600 cycles. Turning to the one with pristine separator, the discharge capacity is $\sim 159 \mathrm{mAh} / \mathrm{g}$ after 130 cycles and then gradually drops to $\sim 94 \mathrm{mAh} / \mathrm{g}$ after 260 cycles.
More critically, using a pre-set amount of $\mathrm{Zn}$ as the anode, the cycling performance of the full cell is further evaluated at the specific negative-to-positive electrode capacity $(\mathrm{N}: \mathrm{P})$ ratios of $10: 1$. The discharge capacity of the full cell with the pristine separator deteriorates rapidly after about 60 cycles, with a capacity of merely $\sim 63 \mathrm{mAh} / \mathrm{g}$ after 80 cycles (Supplementary Fig. 27). On the contrary, the highly improved cycle stability is achieved over 180 cycles (discharge capacity of $\sim 145 \mathrm{mAh} / \mathrm{g}$ ) on the full cell with the Sn-coated separator. Furthermore, we use the commercially available cathode (activated carbon (AC)) to elucidate the benefits of Sn-coated separator. The performance of $\mathrm{Zn} / \mathrm{AC}$ full cells using Sn-coated separator is tested at $12 \mathrm{~A} / \mathrm{g}$. Surprisingly, such cell can stably deliver a discharge capacity of $54 \mathrm{mAh} / \mathrm{g}$ for more than 20,000 cycles (Supplementary Fig. 28b). These observations are in line with the improved lifetime of $\mathrm{Zn} /$ $\mathrm{Zn}$ cell using Sn-coated separator and confirm the benefits in practical electrochemical systems. The performance of our work and other research is summarized in Supplementary Tables 3 and 4. It is found that the stability of our work is competitive with those previous reports.

We note that the Sn element is also highly sodiophilic ${ }^{60,61}$. The strategy of interfacial chemistry regulation may also be applicable 

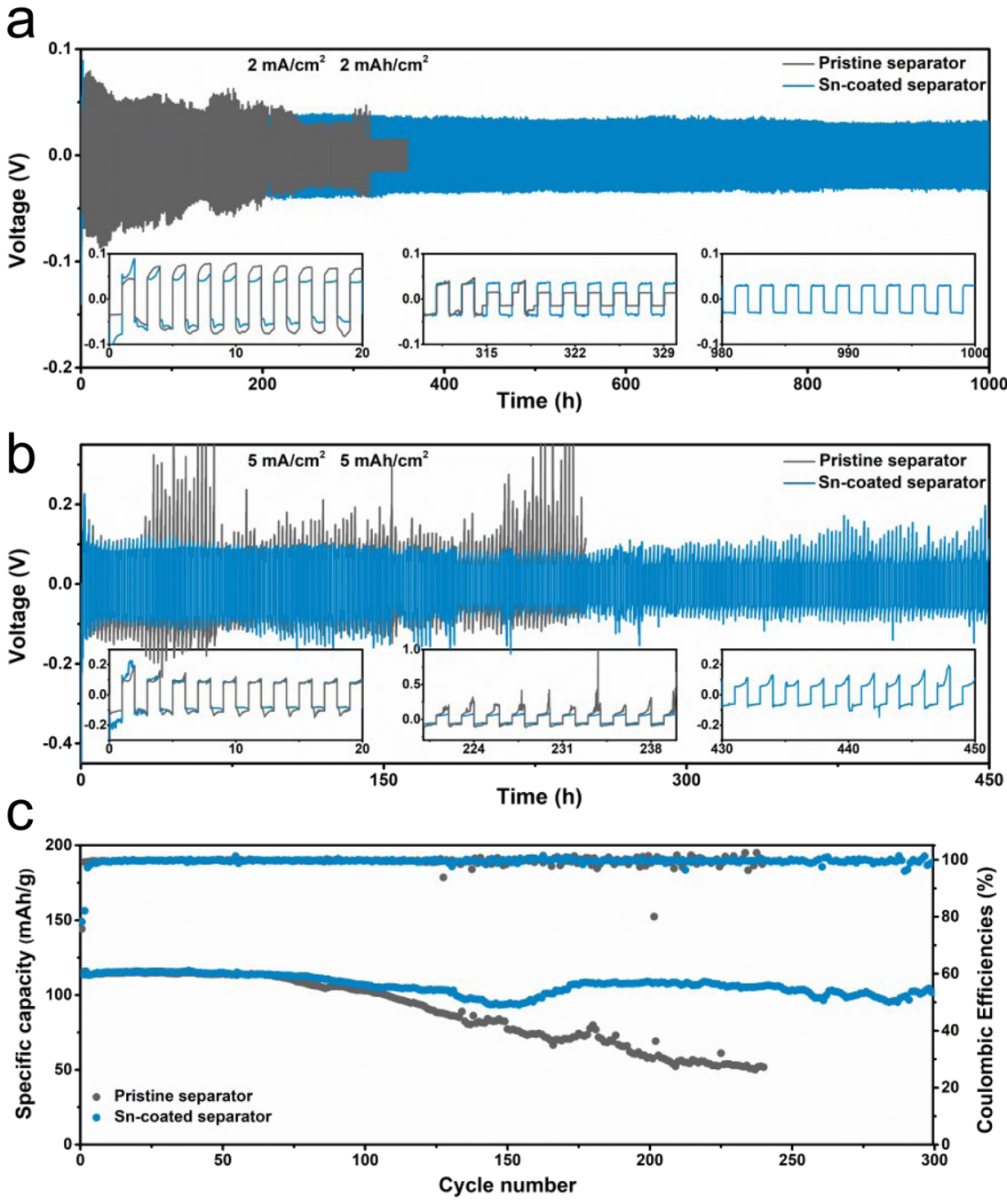

Fig. 6 The electrochemical performances of $\mathbf{N a}$ metal batteries. The cycling performances of $\mathrm{Na} / \mathrm{Na}$ cells using pristine separator and $\mathrm{Sn}$-coated separator are tested at a $2 \mathrm{~mA} / \mathrm{cm}^{2}$ and $2 \mathrm{mAh} / \mathrm{cm}^{2}, \mathbf{b} 5 \mathrm{~mA} / \mathrm{cm}^{2}$ and $5 \mathrm{mAh} / \mathrm{cm}^{2}$. c The cycling performances of Na||NVPF batteries using pristine separator and $\mathrm{Sn}$-coated separator at $0.1 \mathrm{~A} / \mathrm{g}$, with $\mathrm{N}: \mathrm{P}$ ratios of $5: 1$.

to $\mathrm{Na}$ metal anodes, which suffers from similar safety hazards related to $\mathrm{Na}$ dendrites growth ${ }^{62}$. A Na/Na symmetrical cell is fabricated using the Sn-coated separator. After cycling, the $\mathrm{Na}$ deposition on Sn-coated separator could be clearly visualized in the optical image (Supplementary Fig. 29). It would trigger the face-to-face growth of $\mathrm{Na}$ metal on the substrate and separator, which is beneficial to preventing dendrite growth and improving the cyclic stability, as demonstrated earlier in the $\mathrm{Zn}$ metal case. The electrochemical performance adopting $\mathrm{Sn}$-coated separator is evaluated using $\mathrm{Na} / \mathrm{Na}$ symmetric cells. As shown in Supplementary Fig. 30, a prolonged lifetime of over $1200 \mathrm{~h}$ is also realized on the $\mathrm{Na} / \mathrm{Na}$ symmetry cell using the Sn-coated separator compared to that using the pristine separator $(880 \mathrm{~h})$. At a higher current density of $2 \mathrm{~mA} / \mathrm{cm}^{2}$, the cell with pristine separator fails after $\sim 320 \mathrm{~h}$ cycling at a capacity of $2 \mathrm{mAh} / \mathrm{cm}^{2}$, whereas a smooth and stable voltage profile for $1000 \mathrm{~h}$ is observed in the cell with Sn-coated separator at the same test condition (Fig. 6a). Noticeably, the cell with Sn-coated separator could stably operate for $450 \mathrm{~h}$ under a higher current density $(5 \mathrm{~mA} /$ $\left.\mathrm{cm}^{2}\right)$ and cycling capacity $\left(5 \mathrm{mAh} / \mathrm{cm}^{2}\right)$ with only a slightly increased overpotential (Fig. 6b), which should be attributed to the regulated $\mathrm{Na}^{+}$flux and the capability of merging $\mathrm{Na}$ deposition from the anode. In contrast, a dramatically fluctuant voltage profile is displayed in the cell with pristine separator, owing to the unstable electrode/electrolyte interface and the growth of dendrites. It finally ends up at $\sim 230 \mathrm{~h}$ with a huge overpotential up to $1 \mathrm{~V}$. We further apply this strategy to potassium $(\mathrm{K})$ metal anodes and realize a lifetime of $450 \mathrm{~h}$ at a large current density $\left(3 \mathrm{~mA} / \mathrm{cm}^{2}\right)$ and cycling capacity $(3 \mathrm{mAh} /$ $\mathrm{cm}^{2}$ ), as seen from Supplementary Fig. 31. The benefits of adopting the $\mathrm{Sn}$-coated separator are confirmed in the $\mathrm{Na}_{3} \mathrm{~V}_{2}$ ($\left.\mathrm{PO}_{4}\right)_{2} \mathrm{~F}_{3}(\mathrm{NVPF}) / \mathrm{Na}$ full cells with a $\mathrm{N}: \mathrm{P}$ capacity ratio of $5: 1$ (Fig. 6c). The $\mathrm{Cu}$ current collectors deposited with a certain amount of $\mathrm{Na}$ are employed as anodes. Full cells with $\mathrm{Sn}$-coated separator deliver much improved capacity retention than that using a pristine separator. These results demonstrate the feasibility of $\mathrm{Sn}$-coated separator for $\mathrm{Na} / \mathrm{K}$ metal batteries.

\section{Discussion}

The dendritic growth of $\mathrm{Zn}$ is inherently unavoidable, as the process is thermodynamically and kinetically favorable. In view of that, we propose an advanced separator modified by a conductive and zincophilic coating layer, which not only retards the growth of $\mathrm{Zn}$ dendrites but also eliminates the inevitably formed $\mathrm{Zn}$ dendrites. After screening various candidate elements, $\mathrm{Sn}$ is selected because of its electrochemical stability, electrical conductivity, and excellent zincophilicity. As revealed by the 
theoretical simulation, the conductive Sn layer brings about uniform electric field distribution, enabling smooth $\mathrm{Zn}$ deposition on the anode and delaying the formation of $\mathrm{Zn}$ dendrites. In addition, the electrical conductivity and zincophilicity of $\mathrm{Sn}$ coating triggers $\mathrm{Zn}$ deposition on the separator. It merges the $\mathrm{Zn}$ grown from the anode during cycling, eliminating the inevitably formed $\mathrm{Zn}$ dendrites and avoiding short circuits. Consequently, dendrites-free $\mathrm{Zn}$ morphologies and highly prolonged cycling performances $\left(1000 \mathrm{~h}\right.$ at $5 \mathrm{~mA} / \mathrm{cm}^{2}$ for $5 \mathrm{mAh} / \mathrm{cm}^{2}$ and $500 \mathrm{~h}$ at $10 \mathrm{~mA} / \mathrm{cm}^{2}$ for $10 \mathrm{mAh} / \mathrm{cm}^{2}$ ) are realized under rigorous testing conditions, allowing the operation of $\mathrm{MnO}_{2} / \mathrm{Zn}$ full cell with limited excess of $\mathrm{Zn}$ metal. Furthermore, this strategy could also be applied to $\mathrm{Na} / \mathrm{K}$ metal batteries owing to the sodiumphilic/ potassiumphilic nature of Sn. This work provides fresh insights for constructing safe metal batteries by modifying the separator/ electrolyte interface.

\section{Methods}

Preparation of Sn-coated separator. The Sn layer was coated onto a commercially available cellulose separator (thickness of $30 \mu \mathrm{m}$ ) using direct current mag netron sputtering system. The distance between the $\mathrm{Sn}$ target and cellulose separator was $10 \mathrm{~cm}$. The sputtering time was set as $0.5,1,2$, and $5 \mathrm{~min}$ at the power of $50 \mathrm{~W}$. The average loading mass of Sn layer was $\sim 0.06 \mathrm{mg} / \mathrm{cm}^{2}$ for sputtering time of $1 \mathrm{~min}$. Similarly, Ag coating was constructed on cellulose separator after sputtering $1 \mathrm{~min}$. The Sn-coated separator was also prepared using the doctor blading technique. The slurry was prepared by uniformly mixing $90 \mathrm{wt} \%$ $\mathrm{Sn}$ nanopowders $(<150 \mathrm{~nm}$ particle size $)$ and $10 \mathrm{wt} \%$ polyvinylidene difluoride (PVDF) in $\mathrm{N}$-methyl-2-pyrrolidone solvent. The homogeneously mixed slurry was then coated onto the cellulose separator using the doctor-blade method with the minimum thickness grade for the scraper $(25 \mu \mathrm{m})$ to make the Sn-coated separator. For convenience, the sample is marked as DSn-coated separator.

\section{Synthesis of metal-modified Ti foils, $\mathbf{M n O}_{2}$, and NVPF. The slurries were} prepared by uniformly mixing $80 \mathrm{wt} \%$ metal powder (metals including $\mathrm{Sn}, \mathrm{Bi}, \mathrm{Ag}$, $\mathrm{Sb}), 10 \mathrm{wt} \%$ Super P, and $10 \mathrm{wt} \% \mathrm{PVDF}$ in $\mathrm{N}$-methyl-2-pyrrolidone solvent. The metals modified Ti foils (denoted as metal-Ti) were fabricated by casting the corresponding slurries on Ti foil using the doctor-blade method. After drying at $60{ }^{\circ} \mathrm{C}$ for $12 \mathrm{~h}$, metal-Ti foils were then punched into circular disks (diameter of $12 \mathrm{~mm}$ ) prior to use. Similarly, Super P-modified Ti foil (denoted as SP-Ti) was prepared by same procedure, except that the slurry was fabricated by uniformly mixing $90 \mathrm{wt} \%$ Super $\mathrm{P}$ and $10 \mathrm{wt} \%$ PVDF. $\mathrm{MnO}_{2}$ was prepared using the hydrothermal method according to the previous report ${ }^{57}$. Specifically, $2.5 \mathrm{~mL}$ of $1.0 \mathrm{M} \mathrm{H}_{2} \mathrm{SO}_{4}$ and $158 \mathrm{mg}$ of $\mathrm{KMnO}_{4}$ were mixed with deionized water $(30 \mathrm{~mL})$ under magnetic stirring until dissolved. Subsequently, $95 \mathrm{mg}$ of zinc powders were added to the solution and stirred magnetically at $60^{\circ} \mathrm{C}$ for $6 \mathrm{~h}$. The product was then collected by filtration and washed with deionized water until the $\mathrm{pH}$ value was higher than 6 . Finally, the product was dried at $80^{\circ} \mathrm{C}$ for $12 \mathrm{~h}$. NVPF was fabricated by a two-step solid-state reaction ${ }^{63}$.

Characterizations. The coin cells were disassembled to obtain the cycled electrodes. These electrodes were washed by deionized water to remove residual electrolytes before characterization. The SEM images were collected by Tescan VEGA3. The XRD and XPS were recorded by X-ray diffractometer (Rigaku SmartLab) with $\mathrm{Cu} \mathrm{Ka}$ radiation and X-ray photoelectron spectrometer (Nexsa) with $\mathrm{Al} \mathrm{Ka} \mathrm{X}$-ray line, respectively. The thickness of the sputtering Sn layer on separator and Raman measurements were respectively carried out on atomic force microscope (Bruker) and Witec-Confocal Raman system (UHTS 600 SMFC VIS) with a laser wavelength of $532 \mathrm{~nm}$.

Electrochemical measurements. CR2032 coin-type cells were assembled with $2 \mathrm{M}$ $\mathrm{ZnSO}_{4}$ as an electrolyte in the ambient atmosphere. $\mathrm{Zn}$ foils were employed as both the counter and reference electrodes. Ti foil, metal-Ti foil, and $\mathrm{Zn}$ foil were adopted as working electrodes to make $\mathrm{Ti} / \mathrm{Zn}$, metal- $\mathrm{Ti} / \mathrm{Zn}$, and $\mathrm{Zn} / \mathrm{Zn}$ cells, respectively. The pristine and $S n$-coated separator were adopted for comparison. The cycling performances of $\mathrm{Zn} / \mathrm{Zn}$ cells were performed at various current densities and cycling capacities. For $\mathrm{Na}$ and $\mathrm{K}$ batteries, $1 \mathrm{M} \mathrm{NaPF}_{6}$ in diethylene glycol dimethyl ether (DGME), and $1 \mathrm{M}$ potassium bis(fluorosulfonyl)imide in DGME were respectively used as the electrolyte. The CV and EIS measurements were obtained using the BioLogic electrochemical workstation (versatile potentiostat). EIS was performed from $10^{5}$ and $10^{-1} \mathrm{~Hz}$ with a potential amplitude of $5 \mathrm{mV}$. A slurry consisting of $70 \mathrm{wt} \% \mathrm{MnO}_{2}, 20 \mathrm{wt} \%$ Super P, and $10 \mathrm{wt} \%$ PVDF was coated on stainless steel to prepare $\mathrm{MnO}_{2}$ cathode. $\mathrm{Zn}$ foil and $\mathrm{Ti}$ foil with a specific amount of $\mathrm{Zn}$ were paired with $\mathrm{MnO}_{2}$ cathode for full cell evaluation. The electrolyte was 2 $\mathrm{M} \mathrm{ZnSO}_{4}+0.2 \mathrm{M} \mathrm{MnSO}_{4}$, where $\mathrm{MnSO}_{4}$ helps to suppress $\mathrm{Mn}^{2+}$ dissolution ${ }^{64}$. It is found that the $\mathrm{MnSO}_{4}$ additive has a negligible influence on $\mathrm{Zn}$ deposition/ stripping behavior (Supplementary Fig. 32 and Supplementary Note 7). These full cells were tested between 0.8 and $1.9 \mathrm{~V}$.

Theoretical computations. Finite element method conducted by Ansys was adapted to simulate the electric field distribution with the pristine separator and the conductive/zincophilic separator (Sn-coated separator). The pristine separator was modeled as a sieve plate with a thickness of $3.8 \mu \mathrm{m}$, which was composed of rectangular channels with an aperture of $1.0 \mu \mathrm{m}$ and a hole spacing of $1.0 \mu \mathrm{m}$. The potential difference between cathode and anode was set as $0.1 \mathrm{~V}$. The electrical conductivity of anode/cathode and separator was $5.81 \times 10^{7}$ and $1.00 \times 10^{-7} \mathrm{~S} \mathrm{~m}^{-1}$, respectively. The electrical conductivity of $\mathrm{Sn}$ and electrolyte was $9.17 \times 10^{5}$ and $1.00 \mathrm{~S} \mathrm{~m}^{-1}$, respectively.

\section{Data availability}

The data that support the findings of this study are available from the corresponding author upon reasonable request.

Received: 31 October 2020; Accepted: 14 April 2021; Published online: 25 May 2021

\section{References}

1. Shin, J. \& Choi, J. W. Opportunities and reality of aqueous rechargeable batteries. Adv. Energy Mater. 10, 2001386 (2020).

2. Chao, D. et al. Roadmap for advanced aqueous batteries: from design of materials to applications. Sci. Adv. 6, eaba4098 (2020).

3. Zeng, X., Hao, J., Wang, Z., Mao, J. \& Guo, Z. Recent progress and perspectives on aqueous $\mathrm{Zn}$-based rechargeable batteries with mild aqueous electrolytes. Energy Storage Mater. 20, 410-437 (2019).

4. Huang, J., Guo, Z., Ma, Y., Bin, D., Wang, Y. \& Xia, Y. Recent progress of rechargeable batteries using mild aqueous electrolytes. Small Methods 3, 1800272 (2019).

5. Jia, H. et al. Recent advances in zinc anodes for high-performance aqueous Zn-ion batteries. Nano Energy 70, 104523 (2020).

6. Han, C., Li, W., Liu, H. K., Dou, S. \& Wang, J. Principals and strategies for constructing a highly reversible zinc metal anode in aqueous batteries. Nano Energy 74, 104880 (2020).

7. Zhang, Q., Luan, J., Tang, Y., Ji, X. \& Wang, H. Interfacial design of dendritefree zinc anodes for aqueous zinc-ion batteries. Angew. Chem. Int. Ed. 59, 13180-13191 (2020)

8. Song, M., Tan, H., Chao, D. \& Fan, H. J. Recent advances in Zn-ion batteries. Adv. Funct. Mater. 28, 1802564 (2018).

9. Li, H. et al. Advanced rechargeable zinc-based batteries: Recent progress and future perspectives. Nano Energy 62, 550-587 (2019).

10. Liang, P. et al. Highly reversible $\mathrm{Zn}$ anode enabled by controllable formation of nucleation sites for Zn-based batteries. Adv. Funct. Mater. 30, 908528 (2020).

11. Zhao C. Z., et al. An ion redistributor for dendrite-free lithium metal anodes. Sci. Adv. 4, eaat3446 (2018).

12. Qin, Y. et al. Advanced filter membrane separator for aqueous zinc-ion batteries. Small 16, e2003106 (2020).

13. Yang, Q. et al. Dendrites in Zn-based batteries. Adv. Mater. 32, e2001854 (2020).

14. $\mathrm{Li}, \mathrm{Q}$. et al. Dendrites issues and advances in $\mathrm{Zn}$ anode for aqueous rechargeable Zn-based batteries. EcoMat 2, e12035 (2020).

15. Cheng, X. B., Zhang, R., Zhao, C. Z. \& Zhang, Q. Toward safe lithium metal anode in rechargeable batteries: a review. Chem. Rev. 117, 10403-10473 (2017)

16. Yi, Z., Chen, G., Hou, F., Wang, L. \& Liang, J. Strategies for the stabilization of Zn metal anodes for Zn-ion batteries. Adv. Energy Mater. 11, 2003065 (2020).

17. Xie, C., Li, Y., Wang, Q., Sun, D., Tang, Y. \& Wang, H. Issues and solutions toward zinc anode in aqueous zinc-ion batteries: a mini review. Carbon Energy 2, 540-560 (2020).

18. Lin, D., Liu, Y. \& Cui, Y. Reviving the lithium metal anode for high-energy batteries. Nat. Nanotechnol. 12, 194-206 (2017).

19. Guan, Q. et al. Dendrite-free flexible fiber-shaped $\mathrm{Zn}$ battery with long cycle life in water and air. Adv. Energy Mater. 9, 1901434 (2019).

20. $\mathrm{Wu}, \mathrm{Y}$. et al. Ion-sieving carbon nanoshells for deeply rechargeable $\mathrm{Zn}$-based aqueous batteries. Adv. Energy Mater. 8, 1802470 (2018).

21. Yin, Y. et al. Dendrite-free zinc deposition induced by tin-modified multifunctional 3D host for stable zinc-based flow battery. Adv. Mater. 32, e1906803 (2020).

22. Xie, X. et al. Manipulating the ion-transfer kinetics and interface stability for high-performance zinc metal anodes. Energy Environ. Sci. 13, 503-510 (2020).

23. Zeng, Y. et al. Dendrite-free zinc deposition induced by multifunctional cnt frameworks for stable flexible Zn-ion batteries. Adv. Mater. 31, e1903675 (2019). 
24. Lee, J.-H. et al. Dendrite-free $\mathrm{Zn}$ electrodeposition triggered by interatomic orbital hybridization of $\mathrm{Zn}$ and single vacancy carbon defects for aqueous $\mathrm{Zn}$ based flow batteries. Energy Environ. Sci. 13, 2839-2848 (2020).

25. Cai, Z. et al. Chemically resistant $\mathrm{Cu}-\mathrm{Zn} / \mathrm{Zn}$ composite anode for long cycling aqueous batteries. Energy Storage Mater. 27, 205-211 (2020).

26. Huang, J. Q., Guo, X., Lin, X., Zhu, Y. \& Zhang, B. Hybrid aqueous/organic electrolytes enable the high-performance $\mathrm{Zn}$-ion batteries. Research 2019 2635310 (2019).

27. Wang, F. et al. Highly reversible zinc metal anode for aqueous batteries. Nat. Mater. 17, 543-549 (2018).

28. Qiu, H. et al. Zinc anode-compatible in-situ solid electrolyte interphase via cation solvation modulation. Nat. Commun. 10, 5374 (2019).

29. Naveed, A., Yang, H., Yang, J., Nuli, Y. \& Wang, J. Highly reversible and rechargeable safe $\mathrm{Zn}$ batteries based on a triethyl phosphate electrolyte. Angew. Chem. Int. Ed. 58, 2760-2764 (2019).

30. Zhao, J. et al. "Water-in-deep eutectic solvent" electrolytes enable zinc metal anodes for rechargeable aqueous batteries. Nano Energy 57, 625-634 (2019).

31. Garcia, G., Ventosa, E. \& Schuhmann, W. Complete prevention of dendrite formation in $\mathrm{Zn}$ metal anodes by means of pulsed charging protocols. ACS Appl. Mater. Interfaces 9, 18691-18698 (2017).

32. Yang, Q. et al. Do zinc dendrites exist in neutral zinc batteries: a developed electrohealing strategy to in situ rescue in-service batteries. Adv. Mater. 31, e1903778 (2019).

33. Han, D. et al. A corrosion-resistant and dendrite-free zinc metal anode in aqueous systems. Small 16, e2001736 (2020).

34. Deng, C. et al. A sieve-functional and uniform-porous kaolin layer toward stable zinc metal anode. Adv. Funct. Mater. 30, 2000599 (2020).

35. Hao, J. et al. Designing dendrite-free zinc anodes for advanced aqueous zinc batteries. Adv. Funct. Mater. 30, 2001263 (2020).

36. Cao, L., Li, D., Deng, T., Li, Q. \& Wang, C. Hydrophobic organic electrolyte protected $\mathrm{Zn}$ anodes for aqueous $\mathrm{Zn}$ batteries. Angew. Chem. Int. Ed. 59, 19292-19296 (2020)

37. Zhao, Z. et al. Long-life and deeply rechargeable aqueous $\mathrm{Zn}$ anodes enabled by a multifunctional brightener-inspired interphase. Energy Environ. Sci. 12, 1938-1949 (2019).

38. Cao, J., Zhang, D., Zhang, X., Sawangphruk, M., Qin, J. \& Liu, R. A universal and facile approach to suppress dendrite formation for a $\mathrm{Zn}$ and Li metal anode. J. Mater. Chem. A 8, 9331-9344 (2020).

39. Lee, B. S. et al. Dendrite suppression membranes for rechargeable zinc batteries. ACS Appl. Mater. Interfaces 10, 38928-38935 (2018).

40. Hu, J., Yue, M., Zhang, H., Yuan, Z. \& Li, X. A boron nitride nanosheets composite membrane for a long-life zinc-based flow battery. Angew. Chem. Int. Ed. 59, 6715-6719 (2020).

41. $\mathrm{Li}, \mathrm{C}$. et al. Directly grown vertical graphene carpets as janus separators toward stabilized Zn metal anodes. Adv. Mater. 32, e2003425 (2020).

42. Huang, J.-Q., Lin, X., Tan, H., Du, X. \& Zhang, B. Realizing high-performance $\mathrm{Zn}$-ion batteries by a reduced graphene oxide block layer at room and low temperatures. J. Energy Chem. 43, 1-7 (2020).

43. Yang, H. et al. Constructing a super-saturated electrolyte front surface for stable rechargeable aqueous zinc batteries. Angew. Chem. Int. Ed. 59, 9377-9381 (2020).

44. Liu, Y. et al. Making Li-metal electrodes rechargeable by controlling the dendrite growth direction. Nat. Energy 2, 1-10 (2017).

45. Liu, H., Peng, D., Xu, T., Cai, K., Sun, K. \& Wang, Z. Porous conductive interlayer for dendrite-free lithium metal battery. J. Energy Chem. 53, 412-418 (2021).

46. Zou, P. et al. A periodic "self-correction" scheme for synchronizing lithium plating/stripping at ultrahigh cycling capacity. Adv. Funct. Mater. 30, 1910532 (2020).

47. Zhao, Z. et al. Covalent organic framework-based ultrathin crystalline porous film: manipulating uniformity of fluoride distribution for stabilizing lithium metal anode. J. Mater. Chem. A 8, 3459-3467 (2020).

48. $\mathrm{Wu}, \mathrm{C}$. et al. $\mathrm{Mg}$ doped $\mathrm{Li}-\mathrm{LiB}$ alloy with in situ formed lithiophilic $\mathrm{LiB}$ skeleton for lithium metal batteries. Adv. Sci. 7, 1902643 (2020).

49. Chen, X. et al. A "dendrite-eating" separator for high-areal-capacity lithiummetal batteries. Energy Storage Mater. 31, 181-186 (2020).

50. Foroozan, T., Yurkiv, V., Sharifi-Asl, S., Rojaee, R., Mashayek, F. \& ShahbazianYassar, R. Non-dendritic Zn electrodeposition enabled by zincophilic graphene substrates. ACS Appl. Mater. Interfaces 11, 44077-44089 (2019).

51. Hou, Z. et al. Lithiophilic Ag nanoparticle layer on $\mathrm{Cu}$ current collector toward stable Li metal anode. ACS Appl. Mater. Interfaces 11, 8148-8154 (2019).

52. Yan, K. et al. Selective deposition and stable encapsulation of lithium through heterogeneous seeded growth. Nat. Energy 1, 16010 (2016).

53. Yan, C. et al. Architecting a stable high-energy aqueous Al-ion battery. J. Am. Chem. Soc. 142, 15295-15304 (2020).

54. Wan, M. et al. Mechanical rolling formation of interpenetrated lithium metal/ lithium tin alloy foil for ultrahigh-rate battery anode. Nat. Commun. 11, 829 (2020).
55. Safi, I. Recent aspects concerning DC reactive magnetron sputtering of thin films: a review. Surf. Coat. Technol. 127, 203-219 (2000).

56. Ma, L. et al. Realizing high zinc reversibility in rechargeable batteries. Nat. Energy 5, 743-749 (2020).

57. Wang, J., Wang, J.-G., Liu, H., Wei, C. \& Kang, F. Zinc ion stabilized $\mathrm{MnO}_{2}$ nanospheres for high capacity and long lifespan aqueous zinc-ion batteries. $J$. Mater. Chem. A 7, 13727-13735 (2019).

58. Bhoyate, S., Mhin, S., Jeon, J. E., Park, K., Kim, J. \& Choi, W. Stable and highenergy-density $\mathrm{Zn}$-ion rechargeable batteries based on a $\mathrm{MoS}_{2}$-coated $\mathrm{Zn}$ anode. ACS Appl. Mater. Interfaces 12, 27249-27257 (2020).

59. Hao, J. et al. An in-depth study of Zn metal surface chemistry for advanced aqueous Zn-ion batteries. Adv. Mater. 32, e2003021 (2020).

60. Chen, Q. et al. Polymer-inorganic composite protective layer for stable $\mathrm{Na}$ metal anodes. ACS Appl. Energy Mater. 3, 2900-2906 (2020).

61. Chen, Q. et al. Building an artificial solid electrolyte interphase with highuniformity and fast ion diffusion for ultralong-life sodium metal anodes. J. Mater. Chem. A 8, 16232-16237 (2020).

62. Hou, Z. et al. Poly(vinylidene difluoride) coating on $\mathrm{Cu}$ current collector for high-performance Na metal anode. Energy Storage Mater. 24, 588-593 (2020).

63. Bianchini, $\mathrm{M}$. et al. $\mathrm{Na}_{3} \mathrm{~V}_{2}\left(\mathrm{PO}_{4}\right)_{2} \mathrm{~F}_{3}$ revisited: a high-resolution diffraction study. Chem. Mater. 26, 4238-4247 (2014).

64. Pan, H. et al. Reversible aqueous zinc/manganese oxide energy storage from conversion reactions. Nat. Energy 1, 16039 (2016).

65. Shen, C. et al. Graphene-boosted, high-performance aqueous $\mathrm{Zn}$-ion battery. ACS Appl. Mater. Interfaces 10, 25446-25453 (2018).

66. Li, W., Wang, K., Zhou, M., Zhan, H., Cheng, S. \& Jiang, K. Advanced lowcost, high-voltage, long-life aqueous hybrid sodium/zinc batteries enabled by a dendrite-free zinc anode and concentrated electrolyte. ACS Appl. Mater. Interfaces 10, 22059-22066 (2018).

67. Zhao, R. et al. Redirected Zn electrodeposition by an anti-corrosion elastic constraint for highly reversible Zn anodes. Adv. Funct. Mater. 31, 2001867 (2020).

68. He, H., Tong, H., Song, X., Song, X. \& Liu, J. Highly stable Zn metal anodes enabled by atomic layer deposited $\mathrm{Al}_{2} \mathrm{O}_{3}$ coating for aqueous zinc-ion batteries. J. Mater. Chem. A 8, 7836-7846 (2020).

69. Zhao, K. et al. Ultrathin surface coating enables stabilized zinc metal anode. Adv. Mater. Interfaces 5, 1800848 (2018).

70. Kang, L. T. et al. Nanoporous $\mathrm{CaCO}_{3}$ coatings enabled uniform $\mathrm{Zn}$ stripping/ plating for long-life zinc rechargeable aqueous batteries. Adv. Energy Mater. 8, 1801090 (2018).

71. Zhang, Q. et al. The three-dimensional dendrite-free zinc anode on a copper mesh with a zinc-oriented polyacrylamide electrolyte additive. Angew. Chem. Int. Ed. 58, 15841-15847 (2019).

\section{Acknowledgements}

This work was financially supported by the Innovation and Technology Commission (ITF Project ITS/029/17), the Key Project for Basic Research of Shenzhen (No. JCYJ20170818104125570), the Research Grant Council of Hong Kong (GRF project: 15301220), the Hong Kong Polytechnic University (ZVRP, ZVGH), and GuangdongHong Kong-Macao Joint Laboratory (No. 2019B121205001).

\section{Author contributions}

Z.H. and Y.G. contributed equally to the paper. B.Z. and Z.H. conceived the idea and designed the experiments. Z.H. performed the experiments. Y.G. carried the theoretical simulations. B.Z., Z.H., and H.T. analyzed the data. B.Z., Z.H., and Y.G. prepared this manuscript with inputs from all other coauthors. All authors have given approval to the final version of the manuscript.

\section{Competing interests}

The authors declare no competing interests.

\section{Additional information}

Supplementary information The online version contains supplementary material available at https://doi.org/10.1038/s41467-021-23352-0.

Correspondence and requests for materials should be addressed to B.Z.

Peer review information Nature Communications thanks the anonymous reviewer(s) for their contribution to the peer review of this work. Peer reviewer reports are available.

Reprints and permission information is available at http://www.nature.com/reprints

Publisher's note Springer Nature remains neutral with regard to jurisdictional claims in published maps and institutional affiliations. 
(c) (i) Open Access This article is licensed under a Creative Commons Attribution 4.0 International License, which permits use, sharing, adaptation, distribution and reproduction in any medium or format, as long as you give appropriate credit to the original author(s) and the source, provide a link to the Creative Commons license, and indicate if changes were made. The images or other third party material in this article are included in the article's Creative Commons license, unless indicated otherwise in a credit line to the material. If material is not included in the article's Creative Commons license and your intended use is not permitted by statutory regulation or exceeds the permitted use, you will need to obtain permission directly from the copyright holder. To view a copy of this license, visit http://creativecommons.org/ licenses/by/4.0/.

(C) The Author(s) 2021 